\title{
The prevalence of microvascular obstruction in acute myocardial infarction: importance of ST elevation, infarct size, transmurality and infarct age
}

Lowie MR Van Assche ${ }^{1 *}$, Sebastiaan CAM Bekkers ${ }^{2}$, Annamalai Senthilkumar $^{1}$, Michele A Parker ${ }^{1}$, Han W Kim¹, Raymond J Kim

From 2011 SCMR/Euro CMR Joint Scientific Sessions

Nice, France. 3-6 February 2011

\section{Objective}

To assess the prevalence of microvascular obstruction (MO) by delayed-enhancement cardiac magnetic resonance (DE-CMR) in patients with first acute myocardial infarction (AMI) and describe its relationship with type of infarction, infarct size (IS), transmurality, and infarct age.

\section{Background}

MO has been associated with poor LV remodeling and adverse prognosis. The clinical and CMR characteristics of MO have predominantly been examined in patients with ST-segment elevation MI (STEMI). There are no prior studies that have included both STEMI and nonSTEMI patients to allow direct comparison of the prevalence of MO. Additionally, the relationship of MO with IS, transmurality, and infarct age are incompletely understood.

\section{Methods}

We studied 266 consecutive patients from 2 centers (Duke and Maastricht University) with first AMI (elevated biomarkers and angiographically confirmed $\mathrm{CAD})$. Baseline characteristics and the presence of STsegment elevation (2-contiguous leads $\geq 0.2 \mathrm{mV}$ in men and $\geq 0.15 \mathrm{mV}$ in women in leads V2-V3 and/or $\geq 0.1$ $\mathrm{mV}$ in other leads) were recorded. Cine and DE-CMR were performed at $4 \pm 3$ days. IS and transmural extent were measured by planimetry.

${ }^{1}$ Duke University, Durham, NC, USA

Full list of author information is available at the end of the article

\section{Results}

The population consisted of 147 (56\%) patients with STEMI, 2 (0.8\%) with left bundle branch block, and the remaining 117 (44\%) with non-STEMI. The mean age was $59 \pm 13$ years and $68 \%$ were male. The overall observed prevalence of MO was 53\%. IS and transmurality were significantly larger in patients with MO than without $(24 \%$ vs $7 \%, \mathrm{p}<0.0001$; and $83 \%$ vs $56 \%$, $\mathrm{p}<0.0001$, respectively). The prevalence of MO was higher in STEMI than non-STEMI (69\% vs $31 \%$, $\mathrm{p}<0.0001$, Figure 1), however, when IS was large (upper tertile, $>25 \%$ ) or transmural extent was high (upper tertile, $>80 \%)$ the prevalence of MO was similar (93\% vs $92 \%, \mathrm{p}=0.9$; and $90 \%$ vs $85 \%, \mathrm{p}=0.5$, respectively). The prevalence of MO was dependent on both IS and

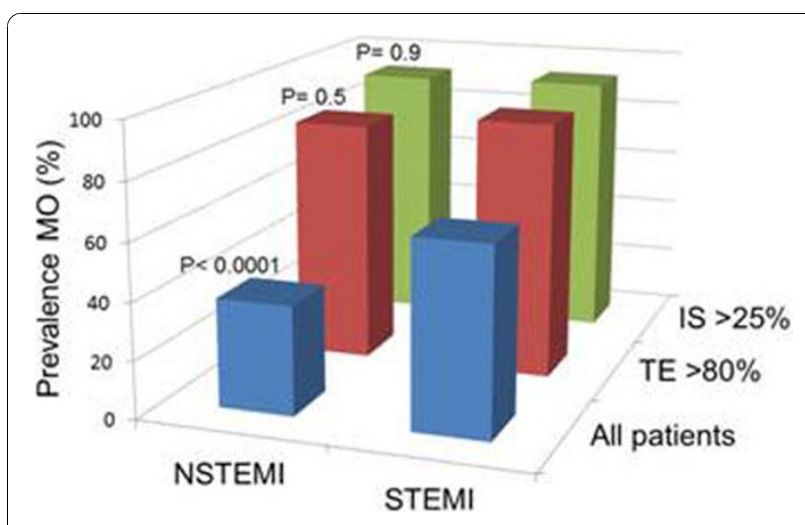

Figure 1 The prevalence of MO for NSTEMI and STEMI in all patients, patients with IS $>25 \%$ (upper tertile) and patients with transmural extent (TE) $>80 \%$ (upper tertile). 


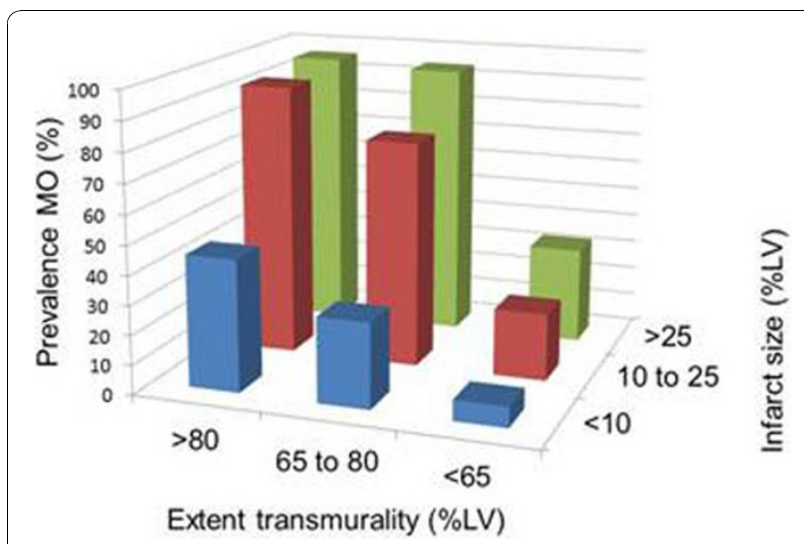

Figure 2 Additive effect of infarct size and transmurality (in tertiles) on the prevalence of $\mathrm{MO}$.

transmurality (Figure 2). Finally, the prevalence of MO was dependent on infarct age: it was similar over the first 6 -days post AMI (days 1-3 =56\%, days 4-6 =56\%) but decreased over the subsequent week (days 7-9 $=42 \%$, days $10-14=30 \%$ ). Multivariable analysis demonstrated that only IS, transmurality, and infarct age were independent predictors of $\mathrm{MO}(\mathrm{p}<0.0001, \mathrm{p}<0.0001$, $\mathrm{p}=0.05$ respectively).

\section{Conclusions}

Microvascular obstruction is more than twice as common in patients with STEMI than non-STEMI, however, the prevalence of MO is similar when accounting for infarct size and transmurality. Only larger infarct size, greater extent of transmurality and earlier infarct age are independent predictors of MO.

\section{Author details}

${ }^{1}$ Duke University, Durham, NC, USA. ${ }^{2}$ Maastricht University, Maastricht,

Netherlands.

Published: 2 February 2011
doi:10.1186/1532-429X-13-S1-P147

Cite this article as: Van Assche et al:: The prevalence of microvascular obstruction in acute myocardial infarction: importance of ST elevation, infarct size, transmurality and infarct age. Journal of Cardiovascular Magnetic Resonance 2011 13(Suppl 1):P147.

\section{Submit your next manuscript to BioMed Central} and take full advantage of:

- Convenient online submission

- Thorough peer review

- No space constraints or color figure charges

- Immediate publication on acceptance

- Inclusion in PubMed, CAS, Scopus and Google Scholar

- Research which is freely available for redistribution

Submit your manuscript at www.biomedcentral.com/submit
C Biomed Central 